\title{
¿Cómo se crea un partido desde la antipolítica? El origen del Partido Sindicalista en la II República Española
}

\author{
How is a party created from antipolitics? \\ The origin of the Syndicalist Party in the Spanish 2nd Republic
}

\author{
MARCELO GUILLÉN
}

Universitat de València

\section{Cómo citar/Citation}

Guillen, M. (2019). ¿ Cómo se crea un partido desde la antipolítica? El origen del Partido Sindicalista en la II República Española. Revista Española de Ciencia Política, 51, 99-121. Doi: Disponible en: https://doi.org/10.21308/recp.51.04

\section{Resumen}

Este artículo profundiza en las razones de la creación de los partidos políticos y para ello he escogido el caso del Partido Sindicalista español. Esta elección responde a la necesidad de conocer los motivos del nacimiento de un partido político desde grupos que los rechazan ideológicamente. Hemos tenido que acudir a un caso histórico como el del movimiento libertario, dadas sus peculiaridades y la dificultad de encontrar ejemplos en la actualidad. El artículo parte de una diferenciación sobre los sentimientos antipartidistas para definir la excepcionalidad del fenómeno y, tras esto, se formula una idea inicial que pretende matizar la teoría de los cleavages de Lipset y Rokkan para la formación de partidos. Posteriormente, sobre la base de la teoría previa, se establecen una serie de hipótesis sobre los factores que favorecen la creación de partidos. El análisis empírico confirma las hipótesis y permite concluir que el nivel organizativo del movimiento libertario y su falta de éxito, junto con la aparición de fallos en el mercado electoral, favoreció la creación del Partido Sindicalista durante la II República. Finalmente, se discute el alcance de los resultados y su relación con supuestos similares y actuales.

Palabras clave: partidos políticos, creación de partidos, sentimientos antipartidistas, antipolítica, anarquismo, sindicalismo, Espańa, Partido Sindicalista, movimiento libertario.

\begin{abstract}
This article deepens into the reasons for the creation of political parties and for that, the case of the Spanish Syndicalist Party has been chosen. This election responds to the need of knowing the causes of the birth of a political party out of groups that ideologically reject them. It has been necessary to resort to a historical case as the
\end{abstract}


libertarian movement, given their peculiarities and the difficulty to find examples nowadays. The article starts with a differentiation on anti-party sentiments to define the exceptionality of the phenomenon and, after that, it formulates an initial idea that aims to clarify Lipset and Rokkan's theory on cleavages for the formation of parties. Subsequently, based on the previous theory, a series of hypotheses is established about the factors that favor the creation of parties. The empirical analysis confirms the hypothesis and it serves to conclude that the organizational level of the libertarian movement and its lack of success, together with failures in the electoral market, favored the creation of the Syndicalist Party during the 2nd Republic. Finally, the scope of the results and their relationship with similar and current cases is discussed.

Keywords: political parties, party creation, anti-party sentiments, anti-politics, anarchism, syndicalism, Spain, Syndicalist Party, libertarian movement.

\section{INTRODUCCIÓN. INTERÉS Y PROBLEMA DE CREACIÓN DE PARTIDOS EN UN CASO HISTÓRICO «CURIOSO»}

¿Por qué se crea un partido desde grupos que rechazaban ideológicamente la representación y organización en torno a partidos políticos? En este artículo analizamos una de las variantes de creación de partidos más atípicas que nos podemos encontrar. Pretendemos esclarecer, a través de un estudio de caso histórico, cómo y por qué, desde posiciones doctrinales de rechazo de la política competitiva y de los partidos políticos, se terminó escogiendo el partido como la opción para canalizar estas ideas y alcanzar sus objetivos. Concretamente, a partir de la teoría previa sobre la creación de nuevos partidos políticos, estudiaremos las razones por las que desde un espacio antipolítico, como fue el movimiento libertario, se creó el Partido Sindicalista (Molas y Culla, 2000: 218-219).

El Partido Sindicalista (PS) se creó en 1934 durante la Segunda República, en un caso que podríamos calificar, cuanto menos, como "curioso». El partido provenía de una de las manifestaciones antipartidistas más relevantes en la historia de nuestro país como fue el movimiento libertario español, el cual tenía como su máximo exponente ideológico al anarquismo y cuya organización referente era la Conferencia Nacional del Trabajo (CNT). Fue creado durante la división del sindicato por una figura importante de este como Ángel Pestańa y algunos de sus seguidores, y por el cual formulaban una doctrina nueva. Dos años después concurrió a sus primeras y únicas elecciones ${ }^{1}$, las generales de febrero de 1936, en las que se integró en la coalición del Frente Popular y obtuvo dos diputados. La historia es bien conocida y en julio de ese mismo año se produjo un levantamiento militar que dio origen a la Guerra Civil. El partido tuvo

1. También llegó a presentar candidatos en las elecciones a compromisarios para elegir al presidente de la República en marzo de ese mismo año. 
que adaptar su actividad y funciones en este contexto ${ }^{2}$ hasta su desaparición, que coincidió con el final del conflicto en 1939. Con su mera existencia, el partido contradecía los principios ideológicos y organizativos de sus raíces, ya que el antipoliticismo era una de las señas doctrinales más importantes del movimiento libertario e impregnaba también las líneas de acción de la CNT (Álvarez Junco, 2010: 18, 20).

Lipset y Rokkan (2001) ya hablaban de la doble función conflicto-integración de los partidos políticos: si bien estos compiten entre sí en el juego democrático, también integran el propio sistema dotándolo de una legitimidad que lo haga estable en el tiempo. Encontramos también muchos partidos que, aun participando en el sistema, tratan de derrocarlo y tienen un impacto deslegitimador, como los partidos antisistema (Sartori, 1999: 165-167). Sin embargo, al fin y al cabo, lo legitiman, ya que sus ideas y objetivos también tienen cabida en su seno. Estos predominaron en el periodo de entreguerras, donde se sitúa nuestro caso de estudio; pero fueron desapareciendo de las democracias tras el fin de la II Guerra Mundial. Posteriormente, y hasta la actualidad, han surgido nuevos partidos que no están en contra del sistema, pero sí rechazan el funcionamiento de sus instituciones y sus élites, recogiendo sentimientos de crítica o desencanto hacia los partidos establecidos. Estos presentan un antipoliticismo en sentido populista, caracterizado por las promesas de cambios estructurales que implican el rechazo a la temporalidad normal de la política y la democracia regida por el largo plazo (Hermet, 2003: 11). Sin embargo, el antipoliticismo anarquista se caracterizaba por el rechazo de la política institucional y parlamentaria derivado de la oposición a todo tipo de autoridad (Paniagua, 1982: 16). Esto hizo al movimiento libertario rechazar los partidos como instituciones que introducían elementos de autoridad central. Así pues, el rechazo de la democracia liberal y de los partidos fue un rasgo característico de los libertarios en nuestro país y que les distinguió de otros movimientos (Álvarez Junco, 2010: 18-20).

Para abordar cómo se creó un partido desde el antipoliticismo anarquista analizamos la creación del Partido Sindicalista. Utilizaremos así mecanismos teóricos actuales de la ciencia política sobre la creación de partidos en un caso del pasado, con la dificultad que esto entraña, ya que nuestro planteamiento no se puede comprobar con ejemplos actuales. Por consiguiente, se asume en nuestro trabajo un conocimiento del contexto de la Segunda República, por lo que nos disculpamos anticipadamente si obviamos algunas explicaciones o conceptos coetáneos que pueden ser más difícilmente asumibles que otros actuales. Actualmente, este tipo de estudios no es frecuente para analizar los partidos en la ciencia política, aunque hay trabajos sumamente interesantes como el de Aldrich (1995) sobre la formación de los partidos estadounidenses. En nuestro país, estos son aún menos habituales, quizás uno de los más destacables

2. Los partidos se tuvieron que adaptar al nuevo contexto de la Guerra Civil: el sistema institucional se mantenía sólo en parte del país, las elecciones ya no se contemplaban y los partidos se enfocaban a tareas fundamentalmente de gobierno para tratar de ganar la guerra o incluso de alcanzar sus objetivos ulteriores más allá de la República. 
que utiliza este tipo de metodología sea el de Miguel Artola (1974), sobre los partidos políticos desde el siglo xIX hasta la Guerra Civil, o los estudios centrados en un caso como los de Oscar Barberá (2006) sobre Unión Democrática de Cataluña o Patricia Gascó (2009) con la UCD.

El análisis de la creación del PS nos puede ayudar a sacar algunas conclusiones que, aunque sean difícilmente generalizables, pueden ser útiles para comprobar y matizar la teoría sobre la creación de partidos en supuestos similares. Esto puede tener especial relevancia en la actualidad, donde surgen nuevos partidos que están aglutinando en votos y en sus organizaciones sentimientos contra los partidos políticos desde movimientos extrainstitucionales. Así pues, el objetivo del trabajo será contrastar nuestras preguntas en forma de hipótesis descriptivas para identificar en el pasado dinámicas en la formación de partidos que contravienen o matizan ideas asumidas en el presente, es decir, comprobaremos esquemas de la actualidad con hechos del pasado. Los resultados de la investigación muestran los factores que favorecieron la creación de un partido desde el movimiento libertario y su antipoliticismo anarquista: entre ellos, la existencia de un fallo en el mercado electoral junto con el alto nivel organizativo que presentó el movimiento que, a su vez, se encontraba en un momento de fracaso o debilidad.

Este artículo se estructura de una manera deductiva: en primer lugar, se explica teóricamente la excepcionalidad del caso para partir de una idea inicial que contraviene la teoría de Lipset y Rokkan sobre la formación de partidos políticos. Asimismo, y también en base a la teoría previa, se formulan una serie de hipótesis sobre algunas de las variables que pueden explicar la creación de partidos desde espacios antipolíticos. En segundo lugar, para comprobar las hipótesis formuladas, se exponen las características doctrinales y organizativas del movimiento libertario y, además, se analizan empíricamente las circunstancias y factores históricos que propiciaron el nacimiento del PS desde este movimiento. Finalmente, se presentan las conclusiones donde se expone la validez de las hipótesis reflexionando sobre su aplicabilidad en algunos casos similares y actuales.

\section{APROXIMACIÓN TEÓRICA PARA EXPLICAR EL ORIGEN PARTIDISTA}

\section{Excepcionalidad del caso}

El antipartidismo o los sentimientos antipartidistas han sido analizados recientemente desde las ciencias sociales (Poguntke, 1996; Scarrow, 1996; Torcal et al., 2001; Bélanger, 2004) para observar el descontento de los ciudadanos con la democracia y el funcionamiento de sus instituciones. Estos autores han planteado, a grandes rasgos y con pequeńos matices en sus interpretaciones, la existencia de dos tipos de antipartidismo: Por un lado, encontramos un antipartidismo generalizado, como el rechazo a los partidos políticos como tales (Poguntke, 1996: 324), arraigado en las tradiciones históricas y en los valores de una cultura política (Torcal, Gunther y Montero, 2001: 
6). Por otro lado, un antipartidismo específico de rechazo a los partidos políticos tradicionales o establecidos en el sistema (Poguntke, 1996: 324). Un rechazo que se explica por la crítica o insatisfacción de los ciudadanos con el desempeño de las élites y de las instituciones democráticas (Torcal, Gunther y Montero, 2001: 5).

Los partidos políticos que han canalizado algunos de estos sentimientos son etiquetados de forma muy diversa por la literatura sobre partidos políticos (Schedler, 1996: 292). Cas Mudde (1996) habla de la paradoja de los que llama «partidos antipartidos» en relación con los partidos de extrema derecha. Partiendo de una distinción similar sobre los sentimientos antipartidistas a la que hemos utilizado, afirma que realmente estos no son partidos antipartido porque no aglutinan sentimientos antipartidistas generalizados o extremistas, sino que recogen sentimientos de antipartidismo específico, que califica de populista, de rechazo a los partidos establecidos o principales (ibid:: 272). Los partidos verdes también se encontraban en una línea similar, ya que cuestionaban la burocracia de los partidos, reclamando nuevos modelos de participación horizontal en las democracias parlamentarias. Estos se llegaron a considerar a sí mismos partidos antipartido (della Porta et al., 2017: 19). En la actualidad, los estudios que tratan sobre el auge de los nuevos partidos con vínculos con los movimientos sociales, los partidos movimiento, apuntan cómo estos recogen también un antipartidismo específico (Morlino y Raniolo, 2017: 77), derivado del rechazo a los partidos políticos principales cuyas políticas cada vez son más parecidas. Estos nuevos partidos como Podemos, Siryza o el Movimiento 5 Estrellas han sido calificados de partidos protesta (ibid.: 49-80) o partidos anti-establishment (della Porta et al., 2017).

Sin embargo, el Partido Sindicalista se creó desde el antipartidismo anarquista que rechazaba a los partidos como organizaciones autoritarias y como instituciones propias de los sistemas democráticos liberales. Supuso así un caso paradigmático o excepcional, ya que muy pocos son los casos constatados de partidos que recojan o provengan de un antipartidismo generalizado. En la literatura se ha vinculado este tipo de sentimientos con la retórica del fascismo histórico y sus líderes; de todos modos, aunque rechazaban los partidos como instituciones (Mudde, 1996: 267) se organizaron en torno a estos. Más allá de nuestro caso, en el movimiento libertario español solo se crearon partidos de manera puntual e infructuosa (Herrerín, 2004: 38, 45-46; Lorenzo, 1972: 295-300)3. Los sentimientos de antipartidismo generalizado, derivados del antipoliticismo anarquista, formaban así parte de la doctrina del movimiento e impregnaban a sus organizaciones y alianzas para defender una interpretación antiautoritaria de la sociedad. Por tanto, su antipartidismo iba más allá de sentimientos individuales de crítica o desafección generalizada hacia los partidos y era un rasgo ideológico del anarquismo como expresión de una fractura social.

El trabajo seminal de Seymour Martin Lipset y Stein Rokkan (2001) se refiere a cómo las divisiones sociales o fracturas (cleavages) cristalizaron en oposición entre

3. Hubo otros intentos de crear partidos desde el movimiento libertario que no llegaron a consumarse. 
partidos, fundamentalmente en el contexto europeo. Aluden, así, a que existen en la sociedad ciertos sistemas de división social y política que durante las formaciones nacionales de los Estados configuraron los diferentes sistemas de partidos. Siguiendo el esquema cuádruple de Talcott Parsons para la clasificación de funciones de un sistema social, formulan un sistema de cleavages o divisiones en las sociedades occidentales sobre los cuales, y en base a procesos diferenciados según los Estados, surgieron los sistemas de partidos.

Lipset y Rokkan presentan un esquema propio según el cuadrante I del modelo parsoniano, sobre el que se forman las alianzas, y donde interpretan las divisiones cruciales y sus expresiones políticas en un espacio bidimensional: la dimensión cultural-territorial (centro-periferia), donde en un extremo $<0>$ se encuentran las oposiciones dentro de la élite nacional, mientras que en el otro $<\mathrm{l}>$ se encuentran las oposiciones locales-regionales (periferia). Y la dimensión funcional, donde en un extremo <a> están las oposiciones de intereses concretos y en el $<\mathrm{i}>$ las oposiciones ideológicas. Finalmente, estas divisiones o conflictos socioculturales se traducen en partidos por las condiciones para la expresión de protesta y representación de intereses en la sociedad, por ciertos umbrales de los sistemas políticos que facilitan o dificultan su entrada y por las normas del sistema electoral que condicionan su éxito. Los partidos políticos presentan así una dicotomía conflicto-integración: forman alianzas estables sobre valores o divisiones en conflicto dentro de un cuerpo mucho más amplio, ya que entran en el Estado y ayudan a legitimarlo y consolidarlo mediante la competición democrática.

Basándonos en la excepcionalidad de nuestro caso histórico, repensamos la teoría sociológica de Lipset y Rokkan (ibid.) sobre la formación de partidos y sistemas de partidos desde divisiones sociales. Si el origen del PS se produce en una época donde la formación de partidos y sistemas de partidos se vincula con el marco de estos autores, sobre nuestro caso formulamos una hipótesis general que pretende cuestionar o matizar sus teorías asumidas en la actualidad: hay partidos políticos que no se crean por la existencia de fracturas sociales, sino por sus condiciones contextuales, ya que hay fracturas que rechazan ideológicamente la organización en torno a partidos. Por consiguiente, para que el Partido Sindicalista naciera de una fractura antipartidista se dieron varios factores que incentivaron su creación.

\section{Factores que favorecen la creación de partidos desde fracturas antipartidistas}

Una vez justificada la especificidad de nuestra variable dependiente, para tratar de responder a nuestra pregunta de investigación concretaremos en forma de hipótesis los factores que influyeron en el proceso de creación del Partido Sindicalista desde el antipartidismo anarquista. Estableceremos así una serie de variables independientes, partiendo de diferentes perspectivas teóricas sobre la creación de partidos, para desarrollar la hipótesis general con la que matizar las ideas de Lipset y Rokkan (ibid.).

Desde que se consolidaron los sistemas de partidos, la teoría se ha centrado en aquellos factores que favorecen el éxito de nuevos partidos en determinados sistemas 
institucionales utilizando fundamentalmente estudios comparados. Estos han destacado la importancia de los factores institucionales (Tavits, 2006), de los sistemas electorales (Hino, 2006; Bollin, 2007), de las viejas divisiones sociales o cleavages (Hauss y Rayside, 1978) o la aparición de nuevas demandas en la sociedad y nuevos partidos que tratan de satisfacerlas (Harmel y Robertson, 1985; Harmel, 1985).

Sin embargo, nosotros queremos resaltar los factores por los que se creó el partido, independientemente de su éxito posterior. Lago y Martínez (2011) argumentan que estos estudios tienen escasa utilidad para análisis de países concretos y en un momento dado; y para solucionarlo, intentan explicar la aparición o creación de los partidos a corto plazo. Algo que los estudios intravariables (Chhibber y Kollman, 2004) tampoco justifican. Así pues, según un estudio empírico sobre las elecciones autonómicas españolas, concluyen que hay tres factores que proporcionan la oportunidad para la aparición de nuevos partidos a corto plazo: los fallos en el mercado electoral, el grado de institucionalización del sistema y el umbral efectivo de los sistemas electorales. Más allá de los factores que pueden favorecer su éxito, exponen que los competidores potenciales dispuestos a entrar en la contienda electoral necesitan ver una oportunidad evidente para hacerlo en las elecciones anteriores (Lago y Martínez, 2011: 13). Si se produce un fallo de mercado electoral, por el cual los partidos no satisfacen las demandas de sus consumidores, los votantes, surge una ventana de oportunidad para que aparezcan otros partidos que sí las satisfagan. Midiendo el nivel de abstención en las elecciones previas a la formación de partidos políticos, concluyen que si aumenta la abstención, es más probable que aparezcan nuevos partidos de cara a las siguientes elecciones. Teniendo esto en cuenta, podemos formular la primera hipótesis en los siguientes términos:

H1. Si se produce un aumento de la abstención que refleje un fallo del mercado electoral, es más probable que posteriormente se creen nuevos partidos para satisfacer las demandas desatendidas.

Además de los factores exógenos, las características de los movimientos o grupos antipartidistas son determinantes para que se creen partidos. Los movimientos sociales articulan ideas y generan alianzas que proporcionan modos, convencionales o no, de participación política alternativos o alejados por su propia naturaleza de los partidos políticos. Siguiendo una visión pragmática, tanto los partidos como los movimientos necesitan recursos, desde materiales a humanos, para poder conseguir sus objetivos. Estos solo pueden ser alcanzados con cierto nivel organizativo que los partidos son capaces de otorgar. De esta forma, se han establecido numerosos vínculos entre movimientos y partidos políticos, a los que se califica de partidos movimiento porque son favorecidos, incentivados e incluso creados por los movimientos sociales (Kitschelt, 2006; della Porta et al., 2017; Morlino y Raniolo, 2017).

En la obra de della Porta y sus coautores se explica la evolución histórica de las relaciones entre los movimientos sociales y los partidos (della Porta et al., 2017 15-24). Esta relación se inició entre los sindicatos y los partidos de obreros de masas, marcados 
por un alto nivel organizativo y de implicación ideológica. Se estableció una relación orgánica entre la representación electoral (partido) y la representación funcional (sindical) de la clase obrera. Más adelante, con la crisis de los partidos de masas, surgieron nuevos movimientos sociales con demandas postmateriales y sentimientos antipartidistas específicos, que reivindicaban una mayor participación horizontal en la política como crítica a las instituciones de las democracias representativas. Por tanto, la brecha entre los movimientos y los partidos se hizo más grande. Los nuevos partidos verdes y de izquierda se relacionaron con los movimientos de una forma mucho más fragmentada, informal y menos integral, ya que perdieron sus redes de apoyo organizativo en los movimientos.

Actualmente, los movimientos sociales continúan formando alianzas más o menos estables con los partidos, pero estos han buscado cooptar a los movimientos sociales, absorber sus identidades y representarlas en las instituciones. Los nuevos partidos movimiento se vieron favorecidos electoral y organizativamente por los movimientos sociales que crecieron durante el ciclo de protestas, ya que ofrecieron canales para articular las quejas y organizar el descontento (ibid., 2017: 183-184). Como hemos visto, independientemente del tipo de relación, los partidos movimiento son herederos en gran medida de los recursos colectivos movilizados por los movimientos con los que interactúan. En cada época, se han aprovechado de diferentes recursos como sus organizaciones, sus identidades o sus apoyos. Como señala Kitschelt, es más probable que los partidos de movimiento aparezcan donde los intereses colectivos son sostenidos por un gran número de miembros, dispuestos a articular sus demandas a través de actividades disruptivas y extrainstitucionales (2006: 282). De esta manera, un nivel organizativo alto en los movimientos sociales donde acumular recursos colectivos, es un factor clave para que creen o se generen vínculos con partidos. Si adaptamos este factor a nuestro caso de estudio, planteamos la segunda hipótesis de la siguiente forma:

H2. Cuanto mayor sea el nivel organizativo de los grupos o movimientos que articulan fracturas antipartidistas, más probable es que desde estas se puedan formar partidos políticos.

Sin embargo, al tratarse nuestro caso de organizaciones con un antipartidismo generalizado, esta variable no puede por si sola explicar el fenómeno. Para que se creen partidos políticos desde este tipo de movimientos organizados, previamente tienen que producirse situaciones que incentiven un cambio ideológico por el que abandonar doctrinalmente su antipartidismo.

Poco sabemos sobre el cambio ideológico en este tipo de supuestos. Desde las teorías de los partidos, los cambios ideológicos se pueden producir por varios factores, tanto externos como internos. Una de las causas más señaladas son los fracasos electorales. Como se argumenta desde una interpretación espacial y la óptica de la elección racional, los partidos cambian para tratar de maximizar el mayor número de votos adaptándose a la competición. De esta forma, si un partido pierde votos, en las siguientes elecciones tiene incentivos para moverse ideológicamente hacia la posición 
maximizadora y tratar de ganar el mayor número de apoyos posible, tal y como reza la "past election hypothesis» de Ian Budge (1994). Si los partidos necesitan principalmente votos, ya hemos dicho que los movimientos necesitan de otros medios y recursos para tratar de alcanzar sus objetivos. Si no son capaces de conseguirlo, tienen incentivos para cambiar sus tácticas y doctrinas e intentar movilizar el mayor número de los recursos colectivos posibles. En este sentido, las alternativas electorales a los movimientos sociales, como los partidos movimiento, se han desarrollado especialmente en las fases decrecientes de dichos movimientos. Como expone della Porta (et al., 2017: 184) cuando «las protestas durante meses y años en las calles no tuvieron éxito, se exploraron varias alternativas». Por lo tanto, el fracaso de las vías extrainstitucionales lleva a repensar los marcos de acción colectiva de los movimientos sociales. Teniendo en cuenta estas condiciones, formulamos una última hipótesis que interactúa con la anterior:

H3. Si se producen fracasos en la movilización de recursos y/o en los medios extrainstitucionales en las organizaciones que rechazan ideológicamente los partidos, es más probable que cambien o abandonen sus principios doctrinales para poder formar partidos políticos.

En definitiva, con estas hipótesis aplicadas a este estudio de caso, el artículo trata de contribuir a la construcción teórica. Frente a los estudios comparados, con la elección de un caso paradigmático con valores extremos se pretende explicar un fenómeno no comprobado para completar o matizar parte de la teoría previa (Sotomayor 2008: 168-169). Para ello, se testarán las hipótesis mediante un análisis intraunidad (Barberà, 2006: 79-80) que nos permita determinar los mecanismos causales por los que varios factores, establecidos desde la teoría, influyeron en la producción del fenómeno planteado. La lógica de este modelo de análisis es similar a la del método histórico, pero este pretende una explicación de los fenómenos guiada teóricamente.

\section{LA CREACIÓN DEL PARTIDO SINDICALISTA DESDE EL ANTIPOLITICISMO ANARQUISTA}

El análisis empírico se estructura en tres partes y en el mismo también recurriremos a argumentos teóricos para aclarar algunas cuestiones. En la primera, se abordan las características doctrinales y organizativas del movimiento libertario para determinar cómo se estructuraban sus ideas antipolíticas y antipartidistas. En la segunda, analizaremos algunos rasgos idiosincráticos de la CNT y explicaremos de forma diacrónica cómo se produjo el conflicto y la división en su interior que desembocaron en la creación del PS. Finalmente, en la tercera parte, explicaremos las causas por las que los factores expuestos en las hipótesis incentivaron la creación del PS desde el movimiento libertario. 


\section{Un partido con raices en el movimiento libertario}

El PS provino del heterogéneo movimiento libertario, pero sería errático afirmar que descendía directamente del anarquismo. Si el anarquismo es lo que podemos considerar una filosofía política, en España se desarrolló pudiéndose incluir en una familia que, partiendo de sus principios, iría más allá, constituyéndose como un fenómeno amplio al que ya nos hemos venido refiriendo como movimiento libertario.

Este movimiento, sea concebido como movimiento social, como cultura política (Navarro, 2014: 151-167) o como la unión de varias de ellas (Herrerín, 2004: 333397), englobaba una gran cantidad de organizaciones, prácticas, militantes e incluso se conformaba de una pluralidad ideológica que lo convertía en un movimiento sumamente heterogéneo (Navarro 2013: 183-189). De todos modos, el antipoliticismo fue un rasgo común al movimiento que se conjugaba con un objetivo: alcanzar el comunismo libertario. Este representaba una sociedad sin Estado, que tras la revolución que acabaría con la democracia burguesa estaría regida por los principios autogestionarios y antiautoritarios. De modo que su antipoliticismo se plasmaba en la oposición a toda autoridad, que era el leitmotiv de las concepciones ácratas y había dado origen al anarquismo como filosofía política (Paniagua, 1982: 16). Esto se reflejó en el rechazo al Estado y sus instituciones y, en definitiva, a toda forma de organización y poder centralizados. Podemos decir así que el PS no nació directamente del anarquismo, pero sí de un movimiento con el que compartía estos principios comunes.

El sindicato fue la manifestación organizativa más importante del movimiento libertario, pese a que en su seno existieran otras. Sobre la CNT se erigió el anarcosindicalismo como organización principal de las ideas libertarias en España. Este sindicato afirmaba su identidad ideológica antiestatal y antipolítica mediante un sindicalismo de acción directa, independiente de los partidos políticos y llamado a transformar la sociedad mediante la revolución, como se reconoció en sus congresos de Sants en 1918 o el de la Comedia, en Madrid, un ańo después (Casanova, 2001: 150). El sindicato fue el instrumento organizativo para alcanzar sus objetivos políticos y que permitía no contradecir su doctrina. El objetivo último era alcanzar el comunismo libertario como un fin que condicionaba también a los medios para alcanzarlo. Por ello, en el movimiento libertario fue identificativo el no aceptar ningún tipo de forma estatal e institucional, ni su participación en ella ni tan solo organizarse en torno a los partidos políticos, ya que suponía introducir o aceptar principios de autoridad.

Si tomamos el análisis de Lipset y Rokkan (2001: 239) para explicar la formación de sistemas de partidos sobre su interpretación del esquema parsoniano, el movimiento libertario se queda en las relaciones entre la comunidad (L) y las alianzas (I). En este punto, los individuos de la comunidad deciden formar varios grupos en casos de rivalidad entre agentes movilizadores; es decir, las familias (L) generan una serie de organizaciones (I). La peculiaridad de nuestro caso es que las relaciones entre las alianzas (I) y la política $(\mathrm{O})$ no se produjeron: los grupos u organizaciones no formaron 
partidos para entrar en las instituciones del Estado porque se negaron a legitimarlo o influirlo por razones doctrinales.

A continuación, nos situamos en el modelo de las divisiones sociales cruciales y sus expresiones políticas elaboradas por Lipset y Rokkan (2001: 240-242). En este, el movimiento libertario y sus organizaciones se encontraban en el extremo del eje $<\mathrm{i}>\mathrm{de}$ oposiciones ideológicas, aquellas donde se identifica el "nosotros» contra el «ellos» y siguen la lógica de amigo-enemigo. La CNT no era así solamente una organización sindical para la defensa de intereses económicos concretos en el eje <a>, de los obreros frente a la burguesía, sino que también promovía una determinada visión de la sociedad, tal y como hicieron muchos partidos obreros con orientación «antisistema» (ibid.: 254). La diferencia era que las razones ideológicas eran ligera pero significativamente diferentes a la de estos partidos, ya que su visión del Estado y de la sociedad les hacía negarse a entrar en la política competitiva ${ }^{4}$. Trataban de superar el sistema capitalista, pero también otras formas de gobierno o administración central que supusieran la introducción de principios de autoridad.

Al situarse en este extremo, este tipo de oposiciones son menos permeables a influencias y las lealtades por encima de estas son menos frecuentes. En la CNT se daba un nivel alto de verzuild: término para explicar una alta caracterización de la oposición, donde «hay alta cristalización de lealtad, la mayoría de los participantes tiende a estar expuesta a mensajes y esfuerzos persuasivos en la misma dirección general en todos sus entornos " 24 horas-7 días" ( $i b i d .: 250$ ). No obstante, no llegaba al nivel de otro tipo de partidos a la hora de impregnar a todos los afiliados del sindicato, ya que había que diferenciar entre simples afiliados, que defendían mejores condiciones de vida para los trabajadores, y sus militantes, que tenían un compromiso alto con las ideas libertarias y la transformación revolucionaria de la sociedad (Monjo, 2003: 477). Pero, al igual que los partidos obreros, las situaciones de clandestinidad y constante oposición reforzaban su mitología, aislándolos de otros segmentos de la sociedad, al contrario de los partidos que ostentaban el poder (Lipset y Rokkan, 2001: 250). En el movimiento libertario se constituyó así Verzuilding o tendencia de formación de asociaciones e instituciones para asegurar la lealtad a las ideas (ibid.: 247). Sus organizaciones reforzaron su doctrina y, pese a que eran de tendencias o corrientes diferentes que defendían sus principios específicos, todas proclamaban el antipoliticismo como mínimo común denominador.

El resultado fue una variedad organizativa, culminada en la CNT, en la que se aglutinaron varias corrientes del denominado movimiento libertario. El sindicato presentó características que no solo se limitaban a la acción sindical, sino también a algunas de las que tienen los partidos políticos, que «no tienen destinatarios en el sentido

4. Los partidos comunistas y fascistas, que tenían también objetivos que iban más allá de la democracia parlamentaria, si hicieron de la lucha electoral un medio para acercarse a estos. Estos partidos presentaban ideologías que permitían adaptar los medios a los fines, pero los principios del movimiento libertario condicionaban los medios a utilizar. 
habitual, apelan a un grupo de la sociedad y provocan reacción de un grupo contrario» (Beyme, 1986: 16)5; pero, en este caso, fuera de la política competitiva. De esta forma, la CNT tenía unos objetivos colectivos y cumplía la función expresiva, ya que elaboraba «una retórica para la traducción de los contrastes de la estructura social y cultural en exigencias y presiones para la acción o la no acción» (Lipset y Rokkan, 2001: 236). Iba más allá de ser una simple facción o grupo de interés que representara el beneficio privado de sus combatientes (Sartori, 1999: 51-58), proponiendo el comunismo libertario como una visión alternativa para organizar la sociedad.

La intención no es analizar si la CNT u otras de sus organizaciones fueron una suerte de partido político antielectoral, sino simplemente aclarar que su papel fue más allá de la actividad sindical tanto en su organización como en sus objetivos. Además, siguiendo la dualidad conflicto-integración de los partidos (Lipset y Rokkan, 2001: 233-237), las organizaciones libertarias y la CNT también cumplían estas funciones, pero desde fuera del sistema, sin legitimarlo y evitando así uno de los niveles del proceso de integración. Estas organizaciones quisieron derrocar al sistema y eran agentes de conflicto contra el mismo y las alianzas que producían otras divisiones sociales. A su vez, también eran agentes de movilización e integración, ya que establecían canales entre las comunidades locales reforzando una determinada identidad política.

En la Segunda República se consolidó un sistema de partidos caracterizado por un pluralismo polarizado (Sartori, 1999: 207) donde, aunque no participaba la CNT, sí era otro sujeto más de acción colectiva. La CNT fue así una suerte de sindicato que iba más allá de sus funciones, mediante el cual organizar las ideas libertarias sin entrar en contradicción con las mismas. Tenía autonomía propia, no se subordinaba a ningún partido y sirvió para reflejar organizativamente gran parte de la pluralidad de ideas del movimiento libertario, estando a su servicio para intentar alcanzarlas. La única diferencia es que sus principios ácratas hacían que, por un lado, la lucha electoral no fuera considerada ni siquiera como un medio circunstancial para lograr sus objetivos ulteriores, aunque esta pudiera servir para reforzar sus ideas y acercarse a sus metas políticas. Por otro lado, tampoco permitían la organización en partidos políticos porque ello suponía introducir principios de autoridad.

Lipset y Rokkan (2001: 259) no contemplaban que hubiera fracturas o divisiones que, tras formar alianzas y arraigar en la sociedad, se pudieran mantener al margen del sistema de partidos por motivos exclusivamente ideológicos y no por los umbrales o factores que faciliten o dificulten su entrada en el mismo. Por estas razones, el anarquismo y las ideas libertarias supusieron una excepción al terminar fraguando organizativamente en un anarcosindicalismo distanciado de los partidos. A pesar de esto, la

5. Habla de cuatro funciones básicas de los partidos políticos: la búsqueda de objetivos, la agregación de intereses, la de movilización y socialización de los ciudadanos en el sistema, sobre todo con las elecciones, y la función de reclutamiento de las élites y formación de gobiernos. Si bien las elecciones y la búsqueda de gobierno se alejan de la CNT, el resto de las funciones sí son, en parte, compartidas. 
CNT cumplía parte de sus funciones y canalizó organizativamente una de las divisiones sociales, la de clase, en torno a una de las oposiciones ideológicas más importantes en la España de finales del xix y principios del xx, la de las ideas libertarias. Una variedad de ideas que, de esta forma, presentó un alto nivel organizativo pese a no organizarse a través de partidos ni participar en la política competitiva.

\section{Conflicto en la CNT y formación del Partido Sindicalista}

En los años previos a la República, las diferencias doctrinales configuraron dos líneas de pensamiento y de acción dentro de la CNT, totalmente diferenciadas y que terminarían por escindir el sindicato durante la República (Navarro, 2013: 189).

Siguiendo a Sánchez-Cuenca (2004: 331), en los partidos se identifican dos tendencias de políticos simultáneas: los dogmáticos, que no pueden asumir los costes de sacrificar la ideología por implementar una política que les pueda acercar a sus fines, y los pragmáticos, que sí pueden asumir estos costes ${ }^{6}$. Nosotros podemos identificar estas dos tendencias de los partidos en las dos líneas que dividieron a la CNT a lo largo de su historia (Casanova, 2001: 148).

Por un lado, los dogmáticos, llamados a sí mismos puristas o idealistas, se organizaron paralelamente en la $\mathrm{FAI}^{7}$. Eran los partidarios de la acción directa y más favorables a la violencia política. Creían que si se apartaban de los medios revolucionarios e introducían fases previas de cara a proclamar el comunismo libertario, esto les alejaría del propio fin. Por otro lado, se encontraba la línea más pragmática llamada la sindicalista o posibilista, que se posicionaba para preservar la independencia del sindicato de las acciones o ideas del anarquismo manteniéndolo en el apoliticismo (Paniagua, 1979: 28; 2001: XXVIII-XXIX) ${ }^{8}$. Estos concebían al sindicato como una organización más burocratizada y disciplinada. Pensaban que a través de la legalización y el refuerzo de la actividad sindical conseguirían arraigar más en los trabajadores y crear las condiciones para una futura revolución. Una vez esta triunfara, contemplaban una fase pre-

6. Se refiere a estos fines como electorales, pero lo podemos hacer extensible a otros fines. En la situación de la CNT sería, por ejemplo, el de adaptarse a la legalidad republicana para ir creando las condiciones favorables a la revolución o incluso llegar a la acción política para acercarse al comunismo libertario.

7. Federación Anarquista Ibérica, creada en 1927 para agrupar a los diferentes grupos anarquistas de la península y servir para reforzar y preservar el dogma e ideología anarquista, lo que intentó que sucediera también dentro de la CNT, dentro de la cual pretendían una superioridad anarquista.

8. El antipoliticismo y el apoliticismo son términos diferentes. El «antipoliticismo» haría referencia a la repulsa a participar en el juego parlamentario o en cualquier acción política. Por su lado, el «apoliticismo» se refiere a la no definición ideológica del sindicato que defendió el sector posibilista o sindicalista de la CNT, contrariamente al sector más purista, que sí estaba a favor de una definición ideológica declaradamente anarquista del sindicato. 
via al comunismo libertario donde el sindicato solucionaría las contradicciones entre sus principios y la instauración de formas de autoridad central (Paniagua, 1982: 47-61). En resumen, ambas tendencias tenían en el comunismo libertario el mismo fin, pero planteaban medios diferenciados para alcanzarlo, aunque, pese a ello, ninguna contemplaba recurrir a los partidos y a la política electoral.

Con la proclamación de la República, triunfaron en el Congreso del Conservatorio de la CNT, en junio de 1931, las tesis de carácter sindicalista o posibilista, siendo el propio Pestańa elegido secretario general. Aunque, de facto, las primeras decepciones con la República y la fuerte oposición del sector más ortodoxo provocaron que se terminaran aplicando sus tesis en el sindicato (Navarro 2013: 196-197). De esta manera, entre 1931 y 1933 se produjo un periodo estratégico marcado por las acciones directas, las huelgas y, sobre todo, por las insurrecciones para proclamar el comunismo libertario (Herrerín, 2014: 170-175). A raíz de esta deriva del sindicato, ya en agosto de 1931 treinta miembros del sector posibilista del anarcosindicalismo, entre los que se encontraba Pestańa, suscribieron el denominado Manifiesto de los Treinta. Por este se afirmaban como corriente sindicalista de la CNT que se oponía a la apuesta insurreccional que, desde el sector anarquista, capitaneado por la FAI, se proponía para derribar el sistema y alcanzar el comunismo libertario. Años antes ya habían puesto de relieve la necesidad de una fase de preparación previa para llegar a poder alcanzar el comunismo libertario. Criticaron la improvisación de las técnicas insurreccionales y se hizo un llamamiento a fortalecer la organización como movimiento revolucionario (Elorza, 1974: 50-51).

El Manifiesto de los Treinta confirmó la brecha y el conflicto que había entre las dos líneas del sindicato, generada ya durante los ańos de dictadura y que la coyuntura republicana terminaría de separar. La República evidenció las diferencias doctrinales y de praxis en el seno del anarcosindicalismo español. El «ciclo insurreccional» casi acaba con el sindicato, ya que a principios de 1934 este había perdido cerca de 500000 afiliados y muchos de sus miembros se encontraban en prisión (Herrerín, 2014: 175; Monjo, 2003: 25). Esta situación provocó la división del sindicato y la línea posibilista terminó abandonando la CNT, en los llamados Sindicatos de Oposición (SS. OO.). Estos ya habían sido conformados un año antes, agrupándose en torno a la Federación Sindicalista Libertaría (FSL) ${ }^{9}$ como organización de defensa de los principios del sector posibilista y apartada de las vías insurreccionales a corto plazo que defendía la FAI. Entre los miembros de esta corriente destacaba el propio Pestaña, que poco después, ya habiendo abandonado la FSL antes de que se produjera la escisión definitiva de los SS. OO. de la CNT, fundó el Partido Sindicalista el 7 de abril de 1934 (Santos, 2012: 332).

Estos sucesos son explicables desde la teoría de los partidos aplicada a la CNT. La rigidez ideológica, término acuñado por Sánchez-Cuenca (2004), impide a los

9. No era otro sindicato como tal, sino que agrupaba a los Sindicatos de Oposición que se oponían a la línea general de la CNT. Era, de alguna forma, análoga a la actividad de la FAI, pero del sector de los llamados sindicalistas. 
sectores dogmáticos de los partidos moderarse. Como explican Lago y Martínez (2011: 8), la ideología supone así un «peso» para los partidos que no les permite cambiar de tácticas para maximizar votos. Cuando esto sucede, en los partidos se originan conflictos entre pragmáticos y dogmáticos, que incluso pueden ocasionar divisiones (Sánchez-Cuenca, 2004: 331). Con el fracaso de las insurrecciones y el descenso de afiliación, los conflictos entre los sectores de la CNT desencadenaron una división. La rigidez ideológica impidió moderarse a los ortodoxos y los dogmáticos se fueron del sindicato hacia dos opciones. Por un lado, la mayoría de los posibilistas fue a otros sindicatos (SS. OO. agrupados en la FSL) donde poder defender sus ideas e implementar sus estrategias. Por otro lado, una minoría liderada por Pestaña creó el Partido Sindicalista, donde sí se produjo una moderación o cambio ideológico, adaptando los medios para acercarse a sus objetivos finales.

\section{¿Por qué al partido político?}

Antes de que Pestaña decidiera crear el Partido Sindicalista, se tuvieron que dar incentivos para que cambiara de ideología. A la postura de los dogmáticos, que no dejaban espacio para las tendencias pragmáticas, se unió el fracaso de sus estrategias con el fallo del modelo insurreccional y el consiguiente descenso de afiliación. En este nuevo contexto Pestańa vio la ocasión de concebir una nueva doctrina. Un año después de la fundación del partido, el propio Pestaña (1974: 796-851) en las primeras páginas de ¿Por qué se constituyó el Partido Sindicalista? ya hablaba de las razones que le llevaron a fundarlo, señalando como primordial, entre otras causas, el fracaso de las insurrecciones:

Tantas y cuantas veces arrastraron a las masas a esa acción revolucionaria, otras tantas fracasaron. Y el proceso revolucionario que ellos y nosotros aceptábamos para el triunfo de la transformación social, fracasaba ruidosamente [...]. La acumulación de tantos factores negativos en la posición que ocupábamos aumentó mis dudas y mis vacilaciones personales. Pero lo que les dio el golpe final, el golpe de gracia, fue la constatación de que la revolución, tal y como nosotros la concebíamos, era imposible de realizar (ibid:: 804-805).

Pestańa consideraba agotada la opción revolucionaria y, por ello, tenía que utilizar otros medios para tratar de conseguir sus objetivos. Para él, las insurrecciones habían demostrado que la estrategia de los dogmáticos o maximalistas había fracasado, no habían conseguido el objetivo del comunismo libertario y, además, habían debilitado al sindicato: «Al llegar a esta conclusión se produjo en mí una crisis (...) equivalía a reconocer que nos fallaba un arma que considerábamos única y exclusiva. El campo de las posibilidades es limitadísimo, pues solo ofrece: o una especie de renuncia a muchas cosas, que eran tanto como caer en un platonismo enervador, o aceptar la lucha política» (ibid:: 805). 
El resultado de la elección lo hemos anticipado. El propio Pestaña reconoció que abandonaban los últimos rescoldos que les unían al anarquismo (ibid:: 830) y que fundaban el sindicalismo político como una nueva doctrina. Por ella, se concebía la formación de un partido para participar en política y crear las condiciones para proclamar el comunismo libertario (ibid:: 809, 814). Además, con la existencia del partido se dotaba al sindicato de autonomía económica.

El fracaso insurreccional trajo consigo una situación precaria para el sindicato. El descenso de afiliados de la CNT significaba un fracaso a la hora de movilizar sus recursos colectivos, que perdía miembros y apoyo para fortalecer su organización e implementar sus estrategias. Igual que los partidos, los sindicatos necesitan movilizar una serie de recursos para la consecución de sus objetivos. En el caso de la CNT, los afiliados eran el indicador más fiable para sopesar el respaldo a las ideas del sindicato y constatar su fuerza organizativa. Es verdad que no todos los afiliados mostraban un alto grado de apoyo a las ideas libertarias ya que, como hemos explicado, había afiliados que lo eran por las ventajas materiales que proporcionaba el sindicato y hacían compatible su afiliación con el voto u otra militancia política. De todas maneras, un descenso en la afiliación sí que produjo, en nuestra opinión, un fracaso a la hora de movilizar los recursos colectivos del sindicato, más allá de cuáles fueran los motivos para militar o abandonarlo. La repuesta de los pragmáticos fue tratar de corregir sus posiciones ideológicas para alcanzar gradualmente el comunismo libertario. Estos provocaron la división del sindicato mediante dos respuestas diferentes: yendo a otros sindicatos donde defender su doctrina más moderada y, como segunda y minoritaria opción, dirigiéndose a la lucha electoral con el partido político. Pero no solo los dogmáticos reaccionaron frente a la precaria situación, sino que las tácticas de la CNT, dominada por los dogmáticos, se moderaron también. Pocos meses después aceptaron una política de alianzas con otras fuerzas políticas a raíz de la preparación de la Revolución de Octubre de 1934, algo que no habían contemplado hasta ese momento y que causó discrepancias con la FAI (Herrerín, 2014: 180184). En resumen, los fracasos en los medios extrainstitucionales, en las insurrecciones, en la movilización de recursos y el descenso de afiliados, provocaron cambios ideológicos y tácticos en todas las tendencias de la CNT.

$\mathrm{Al}$ mismo tiempo que la CNT pasaba por una situación delicada, se produjo un fallo en el mercado electoral. En las elecciones de noviembre de 1933, previas a la formación del PS, se incrementó la abstención en cinco puntos con respecto a las elecciones de 1931 (Ortega, 2002:3). No obstante, no fue un aumento en términos absolutos, sino en porcentaje sobre la población con derecho a voto, ya que las mujeres votaron por primera vez. Pese a esto, un aumento de la abstención representaba un fallo en el mercado de electores y era una oportunidad para que surgieran nuevos partidos (Lago y Martínez, 2011:7) ${ }^{10}$. La CNT y los anarquistas llamaban a la abstención militante,

10. Lago y Martínez (2011: 13) miden el fallo de mercado con el nivel de abstención en las elecciones anteriores a la aparición electoral de los nuevos partidos. En este caso, el PS se presentó en 1936, por lo que tomamos los datos de 1933 . 
con lo que su aumento podría identificarse con el apoyo a las ideas libertarias. Pese a ello, acudiendo directamente a los escritos del propio Pestańa, vemos cómo la abstención sí influyó en sus decisiones.

En un artículo previo a las elecciones de 1933, Pestaña anticipó un aumento del abstencionismo, culpando a los partidos y sus candidatos (1974: 727). Inmediatamente después de los resultados, en otro artículo hablaba de la abstención y el fracaso de las izquierdas concluyendo que «una batalla perdida es el aviso de que hay algo endeble, que falla, a la hora decisiva. Es también lo que obliga a cambiar la táctica en las operaciones futuras» (ibid.:731). En 1935, cuando justifica la creación del PS y su paso a la política, vuelve a señalar los niveles de abstención como algo circunstancial de lo que se debían aprovechar (ibid:: 806). Observamos así cómo la abstención y la derrota de los partidos de izquierdas le alientan definitivamente en su decisión, ya sopesada, de formar el PS. Además, si unimos este fenómeno con el descenso de afiliados de la CNT, indicaban que muchos de estos seguían sin tener una opción que les representara en las elecciones. De esta forma, la crisis del sindicato y el fracaso de la coalición republicano-socialista le incentivaron a intentar llenar ese nicho de mercado en la izquierda política (Artola, 1974: 681) con la formación de un nuevo partido que pudiera satisfacer las demandas de algunos posibles votantes, entre ellos libertarios desencantados y sin referencia electoral.

Por último, además de la ventana de oportunidad que se abría con el fallo en el mercado electoral, el cambio ideológico culminó en la creación de un nuevo partido por otra razón: el alto nivel de estructuración de las ideas previas. Del pensamiento de Pestańa (1974: 796-851) interpretamos tres razones que muestran cómo la creación del PS sirvió para canalizar las ideas revisadas de la CNT.

Primero, el partido era la solución organizativa a los nuevos medios para alcanzar el comunismo libertario ¿Por qué no ir a otros partidos? Pestaña (ibid.: 820-829) explica directamente por qué no ingresó en el PSOE o el PCE, refiriéndose a las diferencias del marxismo con su nueva doctrina. Sus nuevas ideas necesitaban una organización diferente para canalizarlas y no acudir a otra con ideas propias. Cuando renuncian a sus medios lo hacen a parte de su ideología, la cambian, creen que para su objetivo final es necesaria la política y para ello el partido es el nuevo medio para alcanzar sus objetivos, para participar en política e ir gradualmente hacia el comunismo libertario. $\mathrm{Al}$ abandonar la $\mathrm{CNT}$, que cumplía la función expresiva para el anarquismo y las ideas libertarias, el sindicalismo político necesita ahora de una organización referente que haga lo propio, cumpliendo el PS así la función expresiva para las nuevas ideas de Pestaña.

Segundo, el partido era la forma de alejarse de su doctrina, pero también de mantenerse en ella, otorgando coherencia ideológica al cambio doctrinal. Este aparece con una doble función: justificar la nueva ideología, el sindicalismo político, y vincularla con parte de sus ideas precedentes, las antipolíticas. Por un lado, se precisa que la renuncia al antipoliticismo no era total y simplemente afectaba a los medios, adaptándolos para conquistar el mismo fin, el comunismo libertario (ibid.: 770). Por otro lado, con el sindicalismo político el partido es el que interviene en la acción sindical política, 
dejando al sindicato la acción sindical económica para que atiendan las reivindicaciones económicas de los trabajadores (ibid.: 809-820). El partido es un instrumento del sindicalismo para intervenir en política y mantener al sindicato en el apoliticismo que había defendido el sector anarcosindicalista de la CNT (ibid:: 810). De esta manera, tal y como habían hecho los partidos del movimiento obrero, se establecía una relación orgánica sindicato-partido, pero, en este caso, el partido era la correa de trasmisión de las ideas del sindicato. Observamos así una similitud con el laborismo británico basado en el modelo de Gotha invertido, donde eran los intereses del sindicato (Trade Unions británicas) los que primaban y el partido el que estaba a su servicio.

Por último, el nuevo partido cumple una función representativa e instrumental. Pestaña (ibid.: 849) hablaba de la necesidad de «pactos, convenios y alianzas que interesen» con otras fuerzas afines, a lo que hará alusión en diferentes momentos de la historia de PS. Rechazaba la visión de partido único, en alusión a los partidos marxistas, hablando del entendimiento con otras fuerzas. Los partidos cumplen funciones representativas e instrumentales que «fuerzan a los portavoces de los diversos puntos de vista e intereses contrapuestos a llegar a acuerdos, a escalonar peticiones y a agregar presiones» y son fundamentales para tratar de ejercer influencia en los asuntos de una comunidad (Lipset y Rokkan, 2001: 236). Por eso Pestaña forma el partido: el abandono del antipartidismo no solo significa entrar en el sistema, sino aceptar que el comunismo libertario se alcanzaría de forma gradual tras crear las condiciones necesarias por medio de la política. Había que acordar puntos de encuentro y aglutinar nuevas fuerzas como forma más eficaz de poder ejercer influencia y acercarse a sus objetivos. A raíz de estas interpretaciones, el Partido Sindicalista no solo logró coaligarse con otros partidos (Santos, 2012: 344-353), sino también suscribió el pacto del Frente Popular adoptando su programa de mínimos (Artola, 1974: 681-682). Presentaron así dos candidatos en las elecciones de 1936, el propio Pestaña por Cádiz y Benito Pabón por Zaragoza, y ambos obtuvieron actas de diputado.

En definitiva, cuando se produjeron incentivos para el cambio ideológico y apareció una ventana de oportunidad para formar nuevos partidos, la presencia de una organización fuerte que estructuraba las ideas libertarias hizo que Pestaña, tras abandonar parte de estas ideas, formara el Partido Sindicalista.

\section{DISCUSIÓN Y CONCLUSIONES}

Mediante el análisis del movimiento libertario hemos justificado cómo el PS no se creó por la existencia de un cleavage previo. El movimiento libertario estructuró las ideas de una fractura antipartidista en la que no se crearon partidos por sus características ideológicas. El anarquismo impulsó sentimientos antipartidistas generalizados que hicieron que se rechazaran los partidos políticos como instituciones autoritarias, aunque sí se formaron otras organizaciones para canalizar sus ideas y alcanzar sus objetivos. De esta manera, se tuvieron que dar varios factores contextuales para que en 1934 Ángel Pestaña creara el Partido Sindicalista desde un sector de la CNT. 
En 1933, coincidieron un aumento de la abstención en las elecciones, donde retrocedieron los partidos de izquierdas, con una crisis del sindicato por la derrota de las insurrecciones y el descenso de afiliación. Por estos hechos, confirmamos nuestras hipótesis sobre los factores que influyen para que desde una división social antipartidista se formen partidos: el fallo del mercado electoral incentivó la creación de un nuevo partido para intentar llenar el hueco que la izquierda política había dejado (H1). Al mismo tiempo, en el movimiento libertario se produjo un fracaso de las vías extrainstitucionales y en la movilización de recursos que hicieron cambiar de doctrina a los libertarios más pragmáticos (H3). Además, junto con este factor, a partir de las palabras del propio Pestańa justificamos cómo el alto nivel organizativo de las ideas libertarias creó una serie de necesidades que, al producirse el cambio doctrinal, provocaron la creación de un nuevo partido político (H2). Por último, también hay que destacar algunas características idiosincráticas de la CNT, que favorecieron su división y la formación del PS, como observamos en los conflictos desencadenados por la presencia de pragmáticos y dogmáticos en su interior. En resumen, con este caso excepcional confirmamos nuestra hipótesis general por la que matizamos parte de la teoría previa de Lipset y Rokkan (2001): la existencia de una fractura social no propició el nacimiento del PS, ya que al proceder de una fractura ideológicamente antipartidista se tuvieron que dar varios factores que incentivaron su creación.

Por otra parte, hay que precisar que, pese a las condiciones favorables para el cambio doctrinal, solo una pequeña parte del movimiento libertario optó por integrarse en el nuevo partido. Un alto nivel organizativo provoca así un efecto paradójico en movimientos con un antipartidismo extremo: favorece que estos puedan crear partidos si coincide con las otras condiciones establecidas, pero dificulta el abandono de sus principios. La organización canaliza, dota de estructura y refuerza unos principios que son aceptados colectivamente. La CNT y sus organizaciones reforzaron así el antipoliticismo anarquista y su antipartidismo. Por esta razón, pese a los incentivos y la importante presencia de un sector de pragmáticos, fue solo una minoría la que decidió abandonar sus ideas y aceptar el PS, lo que produjo rechazo unánime en las otras corrientes del movimiento libertario.

Con este estudio de un caso paradigmático creemos haber obtenido conclusiones interesantes sobre la formación de partidos políticos. Además, con la dificultad de aplicar parámetros actuales sobre ejemplos históricos, resaltamos también la utilidad de las herramientas teóricas de la ciencia política para explicar casos del pasado. Aun así, es difícil, sin más investigaciones, que podamos hacer generalizables estas conclusiones a supuestos similares, por sus peculiaridades y por la dificultad de encontrarlos ya que, como señalábamos, pocos son los casos de partidos creados desde fracturas o movimientos que rechacen per se a los partidos políticos.

Sin embargo, ya hemos expuesto que en la actualidad muchos de los nuevos partidos provienen de los movimientos sociales y presentan sentimientos de antipartidismo coyuntural. En nuestro país, Podemos y sus vínculos con el $15 \mathrm{M}$ son un claro ejemplo. En comparación con el movimiento libertario, el 15M fue un movimiento social espontáneo que, aunque alejado de la política institucional, no presentó una 
organización sólida y se diluyó mientras Podemos crecía electoralmente (della Porta et al., 2017: 47-50). En la actualidad existe así una relación dialéctica entre los movimientos sociales y los nuevos partidos. Los partidos canalizan parte de los recursos colectivos de los movimientos y se aprovechan electoralmente de ellos, especialmente cuando fracasan (ibid:: 183-184). El PS, al igual que los partidos obreros de masas de su época, surgió de una relación mucho más orgánica con sus movimientos originales. La importancia de los cleavages para definir sus ideologías y la presencia de organizaciones fuertes, creó necesidades para canalizar las divisiones hacia partidos políticos. Sin embargo, los movimientos actuales, poco organizados y con ideologías más débiles o permeables, politizaron el descontento, pero fueron rápidamente atraídos a la política institucional por otros partidos.

Finalmente, a pesar de las peculiaridades de nuestro caso, resaltamos cómo en los movimientos sociales el nivel organizativo y la expresión ideológica de cleavages son factores que favorecen la posibilidad de que estos creen partidos. Unas afirmaciones que solo pretenden ser una reflexión final en relación con supuestos actuales y similares para sugerir posibles puntos de partida de cara a investigaciones futuras.

\section{AGRADECIMIENTOS}

El autor quiere agradecer a Juan Rodríguez Teruel, profesor de la Universitat de València, su colaboración en la elaboración de este artículo, así como los comentarios y sugerencias de los dos revisores anónimos de la Revista Española de Ciencia Política.

\section{Referencias}

Aldrich, John. 1995. Why parties? The Origin and Transformation of Political Parties in America. Chicago: University Chicago Press. Disponible en: https://doi. org/10.7208/chicago/9780226012773.001.0001.

Álvarez Junco, José. 2010. «La filosofía política del Anarquismo», en Julián Casanova (coord.), Tierra y Libertad. Cien años de anarquismo en España. Barcelona: Crítica.

Artola, Miguel. 1974. Partidos y programas politicos. 1808-1936. Tomo I. Los partidos politicos. Madrid: Aguilar.

Barberá, Oscar. 2006. Partits en aliances politiques: rutes del canvi organitzatiu. El cas d'Unió Democràtica de Catalunya (1978-2001). Baras Gómez, Montserrat (dir.), Universitat Autònoma de Barcelona, Barcelona.

Bélanger, Éric. 2004. «Antipartyism and Third-Party Vote Choice», Comparative Political Studies, 37 (9): 1054-1078. Disponible en: https://doi.org/10.1177/ 0010414004268847.

Beyme, Klaus. 1986. Los partidos políticos en las democracias occidentales. Madrid: Centro de Investigaciones Sociológicas. 
Bollin, Niklas. 2007. «New Party Entrance. Analyzing the Impact of Political Institutions», Umea Working Papers in Political Science, 2.

Budge, Ian. 1994. «A new spatial theory of party competition: Uncertainty, ideology and policy equilibria viewed comparatively and temporally», British Journal of Political Science, 24 (4): 443-467. Disponible en: https://doi.org/10.1017/ S0007123400006955.

Casanova, Julián. 2001. «Propaganda por el hecho, sindicalismo y revolución: la presencia del sindicalismo en la España del siglo XX», en Antonio Moya, (coord.), Ideología y movimientos politicos. Las claves de la España del siglo XX. Madrid: Sociedad Estatal España Nuevo Milenio.

Chhibber, Pradeep y Ken Kollman. 2004. The Formation of National Party Systems: Federalism and Party Competition in Canada, Great Britain, India, and the United States. Princeton, NJ: Princeton University Press.

Della Porta, Donatella, Joseba Fernández, Hara Kouki y Lorenzo Mosca. 2017. Movement Parties against Austerity. Oxford: Polity Press.

Elorza, Antonio. 1974. «El sindicalismo de Ángel Pestaña», prólogo en Ángel Pestaña, Trayectoria sindicalista. Madrid: Tebas.

Gascó, Patricia. 2009. UCD-Valencia: estrategias y grupos de poder político. Valencia: Universitat de València.

Hauss, Charles y David Rayside. 1978. «The Development of New Parties in Western Democracies Since 1945", en L. Maisel and J. Cooper, (eds), Political Parties: Development and Decay. Beverly Hills, CA: Sage.

Harmel, Robert. 1985. «On the Study of New Parties', International Political Science Review, 6 (4): 403-518. Disponible en: https://doi.org/10.1177/0192512185 00600403.

Harmel, Robert y John H. Robertson. 1985. «Formation and Success of New Parties», International Political Science Review, 6 (4): 501-523. Disponible en: https:// doi.org/10.1177/019251218500600408.

Hermet, Guy. 2003. "El populismo como concepto», Revista de Ciencia Política, 23 (1): 5-18. Disponible en: https://doi.org/10.4067/S0718-090X2003000100001.

Herrerín, Ángel. 2004. La CNT durante el franquismo. Clandestinidad y exilio (19391975). Madrid: Siglo Veintiuno de España.

Herrerín, Ángel. 2014. «República y sindicalismo: entre la democracia y la insurrección», en Ana Aguado y Luz Sanfeliu, (coords.), Caminos de democracia: ciudadanías y culturas democráticas en el siglo XX. España: Comanus.

Hino, Airo. 2006. New Parties' Success in Western Europe: A Comparative Analysis. Essex: University of Essex.

Kitschelt, Herbert. 2006. «Movement Parties», en Richard S. Katz y William Crotty (eds.), Handbook of Party Politics. Londres; Thousand Oaks: SAGE.

Lago, Ignacio y Ferrán Martínez. 2011. «Why New Parties?», Party Politics, 17 (1): $3-20$.

Lipset, Seymour M. y Stein Rokkan. 2001. «Estructuras de división, sistemas de partidos y alineamientos electorales», en Albert Batlle (ed.), Diez Textos básicos 
de Ciencia Politica. Barcelona: Ariel. Disponible en: https://doi.org/10.1177/ 1354068809346077.

Lorenzo, Cesar. 1972. Los anarquistas españoles y el poder: 1868-1969. París: Ruedo Ibérico.

Molas, Isidre (ed.) y Joan B. Culla (dir). 2000. Diccionari dels Partits Politics de Cataluña: segle XX. Barcelona: Enciclopèdia Catalana.

Monjo, Anna. 2003. Militants. Participació i democracia a la CNT als anys trenta. Barcelona: Laertes.

Morlino, Leandro y Francesco Raniolo. 2017. The impact of the economic crisis on south European democracies. Londres: Palgrave Macmillan. Disponible en: https://doi. org/10.1007/978-3-319-52371-2.

Mudde, Cas. 1996. «The paradox of the anti-party party: Insights from the Extreme Right», Party Politics, 2 (2): 265-276. Disponible en: https://journals.sagepub. com/doi/10.1177/1354068896002002006.

Navarro, Francisco J. 2013. «Diversidad y dualismos. La(s) Cultura(s) Política(s) del movimiento libertario español», en Aurora Bosch, Teresa Carnero y Sergio Valero (eds.), Entre la reforma y la revolución, la construcción de la democracia desde la izquierda. Granada: Comares Historia.

Navarro, Francisco J. 2014. «Irresistibles pervivencias. CNT, anarquía y democracia desde 1939», en Ana Aguado y Luz Sanfeliu, (coords.), Caminos de democracia: ciudadanías y culturas democráticas en el siglo XX. España: Comanus.

Ortega, Carmen. 2002. «Participación y abstención electoral: la Segunda República en perspectiva comparada», Cuadernos Republicanos, 49: 35-53. Disponible en: https://dialnet.unirioja.es/descarga/articulo/1195868.pdf.

Paniagua, Xavier. 1979. Educación y economía en el sindicalismo de Marín Civera. Valencia: Instituto de Ciencias de la Educación.

Paniagua, Xavier. 1982. La Sociedad Libertaria: agrarismo e industrialización en el agrarismo español (1930-1939). Barcelona: Crítica.

Paniagua, Xavier. 2001. «Estudio preliminar: Marín Civera y la cultura popular. Orto (1932-1934)», en Xavier Paniagua, (ed.), Orto (1932-1934): Revista de Documentación Social. Alzira: Centro Francisco Tomás y Valiente UNED, Fundación Instituto de Historia Social.

Pestaña, Ángel. 1974. Trayectoria Sindicalista. Madrid: Tebas.

Poguntke, Thomas. 1996. «Anti-party sentiment. Conceptual thoughts and empirical evidence: Explorations into a minefield», European Journal of Political Research, 29 (3):319-344. Disponible en: https://doi.org/10.1111/j.1475-6765.1996.tb00655.x. Sánchez-Cuenca, Ignacio. 2004. «Party Moderation and Politicians' Ideological Rigidity», Party Politics, 10 (3): 325-342. Disponible en: https://doi.org/10.1177/ 1354068804039120.

Santos, María-Cruz. 2012. Ángel Pestaña: Caballero de la Triste Figura, Barcelona: EAE Editorial Académica Española.

Sartori, Giovanni. 1999. Partidos y sistemas de partidos: marco para un análisis. Madrid: Alianza Editorial. 
Scarrow, Susan. 1996. «Politicians against parties: Anti-party arguments as weapons for change in Germany», European Journal of Political Research, 29 (3): 297-317. Disponible en: https://doi.org/10.1111/j.1475-6765.1996.tb00654.x.

Schedler, Andreas. 1996. "Anti-Political-Establishment Parties», Party Politics, 2 (3): 291-312. Disponible en: https://doi.org/10.1177/1354068896002003001.

Sotomayor, Arturo. 2008. «Los métodos cualitativos en la ciencia política contemporánea: Avances, agendas y retos», Politica y Gobierno, 15 (1): 159-179.

Tavits, Margit. 2006. "Party System Change: testing a model of new party entry», Party Politics, 12 (1): 99-119. Disponible en: https://doi.org/10.1177/135406880 6059346.

Torcal, Mariano, Richard Gunther y José R. Montero. 2001. Anti-party sentiments in Southern Europe. Madrid: Instituto Juan March de Estudios e Investigaciones. Disponible en: https://doi.org/10.1093/0199246742.003.0010.

Presentado para evaluación: 27 de julio de 2018.

Aceptado para publicación: 29 de septiembre de 2019.

\section{MARCELO GUILLÉN}

marceloguillen_7@hotmail.com

Licenciado en Ciencias Políticas y de la Administración por la Universidad de Valencia, con una estancia de nueve meses en la Universidad Complutense de Madrid en el marco del programa SICUE y la beca SENECA. Máster interuniversitario en Historia Contemporánea en la Universidad de Valencia, con la realización del trabajo de fin de máster Una aproximación a la ideología del Partido Sindicalista, que aúna una perspectiva politológica e histórica. Actualmente es estudiante de doctorado en la línea de Ciencia Política en el Departamento de Derecho Constitucional, Ciencia Política y de la Administración de la Universidad de Valencia, donde realiza una tesis doctoral sobre el cambio ideológico y la influencia de los nuevos partidos políticos en la Comunidad Valenciana. 